Article

\title{
Influence of Hardness, Matrix and Carbides in Combination with Nitridation on Abrasive Wear Resistance of X210Cr12 Tool Steel
}

\author{
Martin Orečný ${ }^{1, *}$, Marián Buršák ${ }^{1}$, Martin Šebek ${ }^{2}$ and Ladislav Falat ${ }^{2}$ \\ 1 Faculty of Metallurgy, Institute of Materials, Technical University of Košice, Letná 9, Košice 04200, Slovakia; \\ marian.bursak@tuke.sk \\ 2 Insitute of Materials Research, Slovak Adacemy of Sciences, Watsonova 47, Košice 04001, Slovakia; \\ msebek@saske.sk (M.Š.); lfalat@saske.sk (L.F.) \\ * Correspondence: martin.orecny@tuke.sk; Tel.: +421-55-602-2776 \\ Academic Editor: Hugo F. Lopez \\ Received: 19 May 2016; Accepted: 13 September 2016; Published: 2 October 2016
}

\begin{abstract}
Materials used in abrasive wear conditions are usually selected according to their microstructure and hardness, however, other factors such as grain size, matrix saturation, carbides size and morphology are rarely considered. Therefore, the present study deals with the influence of different heat and chemical-heat treatments including their combination on abrasive wear resistance of X210Cr12 tool steel. The effects of material hardness, carbide morphology and microstructure on wear resistance after quenching and nitriding were also investigated. One sample series was quenched after austenitization at $960^{\circ} \mathrm{C}$ for $20 \mathrm{~min}$ and tempered at $180^{\circ} \mathrm{C}$ for $2 \mathrm{~h}$. The second sample series was quenched from $1060^{\circ} \mathrm{C}$ austenitization for $20 \mathrm{~min}$ and afterwards twice tempered at $530{ }^{\circ} \mathrm{C}$ for $1 \mathrm{~h}$. From both the quenched and tempered states, one half of the samples was gas nitrided in $\mathrm{NH}_{3}$ atmosphere for $3 \mathrm{~h}$ and then diffusion annealed in $\mathrm{N}_{2}$ atmosphere for $4 \mathrm{~h}$. Abrasion wear tests were performed by sliding the samples on $\mathrm{Al}_{2} \mathrm{O}_{3}$ paper. The samples weight loss was considered the main criterion for the wear resistance evaluation. The microstructures, nitrided layers and worn surfaces were observed using SEM microscopy. The highest abrasion wear resistance was obtained for the nitrided samples that were previously quenched from $1060^{\circ} \mathrm{C}$ and tempered at $530{ }^{\circ} \mathrm{C}$.
\end{abstract}

Keywords: abrasion wear; nitriding; wear resistance; carbides; hardness

\section{Introduction}

One of the most common failures of mechanical parts is caused by abrasive wear. The wear occurrence causes significant degradation of structural parts surfaces leading to their decreased functionality, higher maintenance times, and repair costs. Abrasive wear occurs in conditions at which the working tool surfaces get in contact with hard materials such as sand, rocks, ceramic powders or small metallic particles created from worn surfaces by contact fatigue loading. The general criterion for abrasive wear is usually related to the hardness of the material. However, this rule is valid only for the materials of the same material group [1]. Research findings in the field of tool steels processing indicate that material wear decrease can be achieved by increasing the martensite volume fraction and its hardness [2]. If a material has to be used in abrasive wear conditions, the additional factors such as grain size, chemical composition, matrix saturation, carbide size and morphology, particle pressure and abrasion particle size have to be taken into account besides the microstructure type and hardness. The results of the study [3] have shown that in the case of non-heat treated materials the wear is a function of abrasive particle size. Blau and Dehoff [4] investigated the influence of particle reusing. They concluded that the reused abradant reduces the wear rate, because it gets rounded during the testing. Another very important factor is the material grain size. In the work [5] Deng et al. investigated 
a low alloy martensitic steel with $\mathrm{Ti}$ additions used for the grain refinement. The steel was compared with a higher alloyed steel and showed improved abrasion wear resistance. Thus it has been concluded that the higher wear resistance can be obtained for finer grained materials. This rule is valid for wear and also for fatigue resistance [6]. The study by Gural [7] investigated the influence of the material grain size on the sliding wear behavior. It has been confirmed that the finer martensite exhibited higher hardness and lower surface friction resulting in wear reduction. As mentioned before, the preferred microstructure for the abrasion wear conditions consists of hard martensite. Bakshi et al. [8] studied the effects of several microstructure types including very fine pearlite, nanostructured bainite and martensite on abrasion wear resistance. The studied microstructures were free of carbides. It has been revealed that the nanostructured bainite, additionally hardened during the abrasion wear process, showed the best abrasion wear resistance. In contrast, the martensite exhibited some softening during the abrasion wear test. The abrasion wear resistance of D2 steel with multiple stages of heat treatment was investigated in [9]. The high chromium steel was tempered at different temperatures to investigate the matrix, carbide and retained austenite influence on the abrasion wear resistance. The authors found out that the highest wear resistance was obtained for the martensitic microstructure with fine carbides. Higher tempering temperatures caused carbides coarsening and matrix softening, which resulted in a higher wear rate. The authors concluded that the morphology of the carbides played the main role in the wear resistance. It is well known that with increasing alloying content and carbide volume fraction of steel the abrasive wear resistance increases. The higher alloying leads to the increase of material price, more difficult machining and heat treatment. Therefore, surface modifications of steels are usually performed to increase their wear resistance and lifespan. Surface nitridation represents one of possible treatments of steels aiming for the achievement of superior wear and tribological resistance, increased surface hardness and corrosion resistance [10]. The nitrided surfaces are usually composed of $\varepsilon\left(\mathrm{Fe}_{2-3} \mathrm{~N}\right)$ and $\gamma^{\prime}\left(\mathrm{Fe}_{4} \mathrm{~N}\right)$ phases which are very hard but also very brittle [11,12]. The grain size has also its limitations in the process of nitriding. In the work [13] the combined effects of shot peening and nitriding were investigated. The shot peening before nitriding resulted in severe microstructure refinement, achieving an average grain size of about $500 \mathrm{~nm}$. Such a refinement improved the nitrogen diffusion capability but it resulted in an extremely thick compound nitrided layer, which is generally not desired for use in abrasion wear conditions. Practical experience indicates that the compound layer has to be kept at minimum, which can be achieved by a controlled nitriding process. Conventional gas nitriding with diffusion annealing represents a controlled nitriding process enabling achievement of results comparable to those that can be obtained by plasma nitriding [14-17].

In this work, X210Cr12 tool steel was selected as experimental material. It represents a high carbon chromium tool steel that possesses a good abrasive and adhesive wear resistance, high compressive strength and good dimensional stability. The steel contains coarse primary chromium carbides that cannot be dissolved when quenching from temperatures below $970{ }^{\circ} \mathrm{C}$. The high carbon and chromium content of the steel enables it to achieve secondary hardness under 58 HRC (Hardness Rockwell Cone) $[17,18]$. The steel was treated in two different ways to obtain different levels of the matrix saturation and different carbide morphology. Gas nitriding with subsequent diffusion annealing was applied for the quenched and tempered samples prepared by two different regimes aiming for improvement of the surface hardness and tribological properties. From the performed tests it has been found out that the surface hardness evaluation alone may be misleading for the selection of the material and its heat treatment for use in abrasion wear conditions. The nitriding experiments clearly showed their potential for the improvement of surface hardness and abrasive wear resistance depending on the initial microstructure.

\section{Materials and Methods}

X210Cr12 tool steel was selected for the experimental program. This steel is designed for cold working but it can also be treated to achieve secondary hardness when it is quenched from the temperatures ranging between $1040^{\circ} \mathrm{C}$ and $1100{ }^{\circ} \mathrm{C}$ and subsequently tempered in the range from 
500 to $550{ }^{\circ} \mathrm{C}$. This heat treatment enables more chromium carbides to dissolve during austenitization as well as saturating the matrix with chromium and carbon. For the experiments 40 roller samples (20 $\mathrm{mm}$ in length, $6 \mathrm{~mm}$ in diameter) were manufactured. The chemical composition of the steel is documented in Table 1.

Table 1. Chemical composition of X210Cr12 tool steel [wt \%].

\begin{tabular}{cccccccccc}
\hline $\mathbf{C}$ & $\mathbf{S i}$ & $\mathbf{M n}$ & $\mathbf{C r}$ & $\mathbf{S}$ & $\mathbf{P}$ & $\mathbf{M o}$ & $\mathbf{N i}$ & $\mathbf{V}$ & $\mathbf{F e}$ \\
\hline 2.07 & 0.33 & 0.4 & 11.6 & 0.021 & 0.024 & 0.13 & 0.25 & 0.06 & bal. \\
\hline
\end{tabular}

According to the steel data sheet [19], the recommended heat treatment consists of austenitization in the temperature range between $940{ }^{\circ} \mathrm{C}$ and $970{ }^{\circ} \mathrm{C}$, oil quenching and final tempering in the temperature range from $100{ }^{\circ} \mathrm{C}$ to $200{ }^{\circ} \mathrm{C}$. The first series of 20 samples was heat treated according to the regime schematically shown in Figure 1a, denoted as heat treatment " $\mathrm{A}$ ". One half of the samples after the " $\mathrm{A}$ " treatment, i.e., 10 pieces, was gas nitrided and diffusion annealed. Nitriding with diffusion annealing is a controlled process of nitriding in gas atmosphere. The process of gas nitriding with diffusion annealing is performed in two steps. In the first step the sample surface is enriched with nitrogen at $520{ }^{\circ} \mathrm{C}$ for $3 \mathrm{~h}$ in $\mathrm{NH}_{3}$ atmosphere. After $3 \mathrm{~h}$ the $\mathrm{NH}_{3}$ gas is pumped out and the inert $\mathrm{N}_{2}$ gas is pumped in. During this second stage the diffusion annealing process takes place across the next $4 \mathrm{~h}$. The surface enriched with nitrogen serves as an internal source of nitrogen. Diffusion annealing reduces or completely eliminates the undesired compound layer and forms a continual hardness profile of the layer. The described treatment is referred as " $\mathrm{B}$ ", and is documented in Figure $1 \mathrm{~b}$.
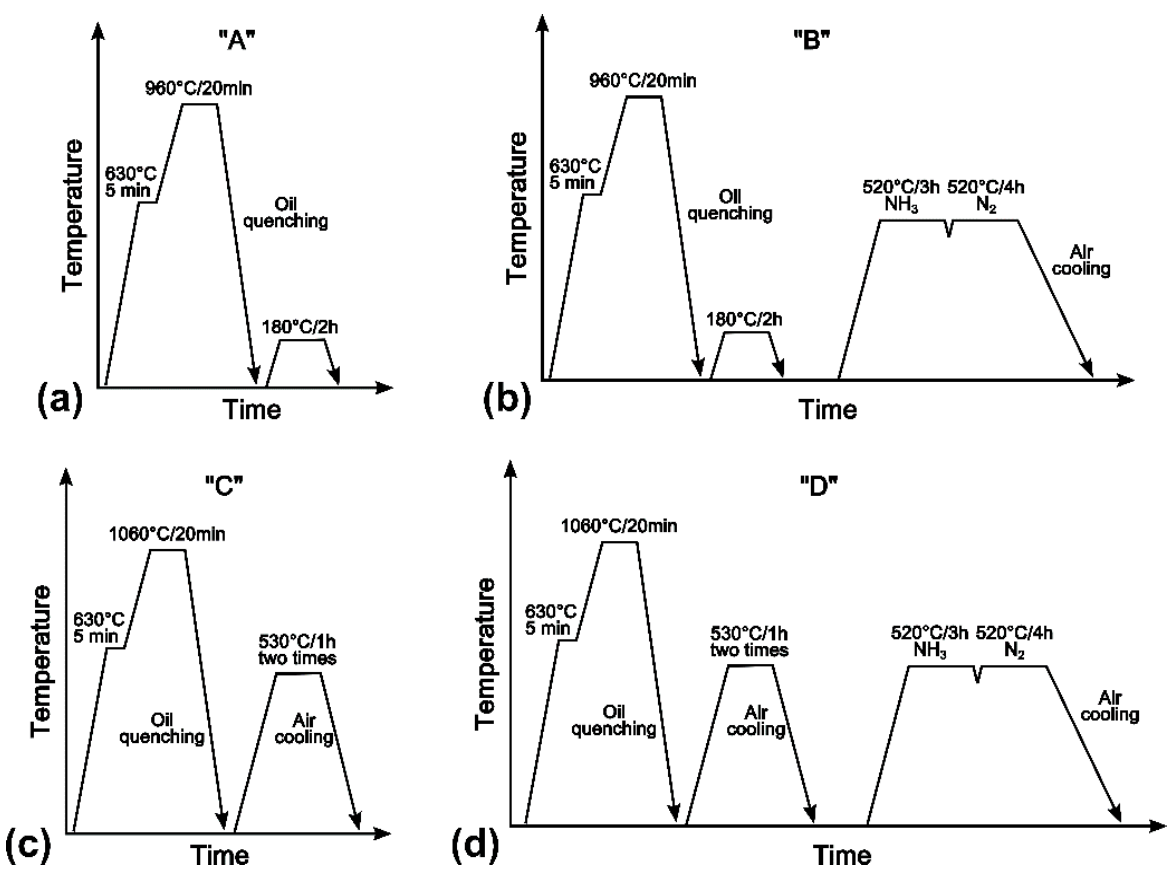

Figure 1. Schematic representation of individual processing treatments of $\mathrm{X} 210 \mathrm{Cr} 12$ tool steel: regime " $\mathrm{A}$ ", involving lower temperature quenching and tempering for primary carbides preservation within fine-grain microstructure (a); regime " $\mathrm{B}$ ", involving the combination of regime " $\mathrm{A}$ " with nitriding (b); regime " $\mathrm{C}$ ", involving higher temperature quenching and tempering for obtaining secondary hardness $(\mathbf{c})$; regime " $\mathrm{D}$ ", involving the combination of regime " $\mathrm{C}$ " with nitriding $(\mathbf{d})$.

The second series of 20 samples was quenched from a higher temperature to dissolve the carbides. The steel was austenitized at $1060{ }^{\circ} \mathrm{C}$, oil quenched and twice tempered at $530{ }^{\circ} \mathrm{C}$ for $1 \mathrm{~h}$. This treatment is referred as " $\mathrm{C}$ " and is documented in Figure 1c. A half of the samples after 
" $\mathrm{C}$ " treatment, i.e., 10 pieces, was gas nitrided with diffusion annealing. This process is referred as " $\mathrm{D}$ " and it is schematically illustrated in Figure 1d. The purpose of the quenching, tempering and nitriding with diffusion annealing is to create a hard layer, with high residual stress near the surface, thus achieving superior tribological properties [10]. The temperature of nitriding and diffusion annealing needs to be lower than the tempering temperature to avoid core softening. Hardness values obtained after the quenching and tempering were measured using Wilson Hardness UH 250 hardness tester (ITW Test \& Measurement GmbH, Esslingen, Germany) and the HRC scale was considered. The microstructures and nitrided layers were characterized using optical microscope Olympus GX71 (Olympus corp., Tokyo, Japan) and scanning electron microscope (SEM) JEOL JSM-7000F (Jeol Ltd., Tokyo, Japan) with an EDX analyzer (Jeol Ltd., Tokyo, Japan). The retained austenite was measured by X-ray diffraction using a Philips X'Pert Pro XRD device (Philips, Eindhoven, The Netherlands). Microhardness profiles of the nitrided layers were measured by a LECO LM700AT Vickers hardness tester (Leco corp., St. Joseph, MI, USA) and the $\mathrm{HV}_{0.05}$ scale was considered. For practical reasons the approximate HRC values were also presented. The conversion from microhardness values to HRC values was done automatically by the microhardness tester (Leco corp., St. Joseph, MI, USA). The worn surfaces were studied and evaluated using SEM. The samples were tested on a rolling machine AGP-1 (WPM Leipzig, Leipzig, Germany) with abrasive papers with $\mathrm{Al}_{2} \mathrm{O}_{3}$ particles, paper grain 120. After each sample, the paper was replaced by a new one to avoid the presence of used abrasive particles. The principle of the wear test is documented in Figure 2. The sliding distance had to be kept short in order to avoid removing of nitrided layers during the testing which otherwise would deform the test results. Therefore the sliding distance was set to $40 \mathrm{~m}$ and the applied force on the samples was $5 \mathrm{~N}$. The sample had to move from the wheel edge to the center of the wheel with a constant velocity. Before the abrasive wear, the samples were cleaned by ultrasound then weighted on a KERN ABJ 120-4M scale (KERN \& SOHN GmbH, Balingen, Germany) with the accuracy of $\pm 0.0001 \mathrm{~g}$. After the abrasive wear test the samples were again ultrasonically cleaned and weighted. The sample weight loss was considered as the main criterion of abrasive wear resistance.

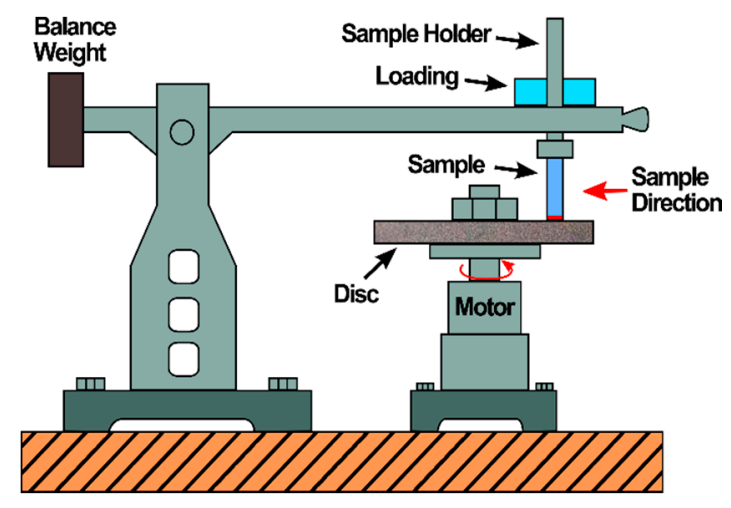

Figure 2. Schematics of AGP-1 abrasive wear test.

\section{Results}

\subsection{Materials and Microstructure}

The purpose of quenching $\mathrm{X} 210 \mathrm{Cr} 12$ steel from $960^{\circ} \mathrm{C}$ is to keep the grain size as small as possible and to avoid the dissolution of the primary carbides. The carbides in this case improve the steel hardness and wear resistance. The microstructure of the steel is composed of martensite, coarse primary carbides and retained austenite. In this case the amount of retained austenite was $24 \mathrm{vol} \%$.

The purpose of hardening the $\mathrm{X} 210 \mathrm{Cr} 12$ steel from a higher temperature is to dissolve the carbides as much as possible. After the quenching from $1060{ }^{\circ} \mathrm{C}$ the steel contained about $10 \%$ undissolved primary carbides and retained austenite. The tempering transforms the retained austenite to martensite 
and also causes the precipitation of carbides in martensitic matrix. The microstructures after " $\mathrm{A}$ " and " $\mathrm{C}$ " treatment are documented in Figure 3a,b.

In the case of heat treatment " $\mathrm{A}$ " the steel hardness after quenching was $61.5 \mathrm{HRC}$. After subsequent tempering the hardness was $61 \mathrm{HRC}$. Low temperature tempering causes formation of the $\varepsilon$ carbide, which does not affect the steel hardness but reduces the brittleness of the steel.

After the quenching the steel from a higher temperature $\left(1060{ }^{\circ} \mathrm{C}\right)$, the obtained secondary hardness of the steel was $53 \mathrm{HRC}$, which was also caused by the presence of retained austenite. Further tempering transforms the austenite into martensite and also causes the carbide precipitation in the steel matrix resulting in hardness increase to $57 \mathrm{HRC}$. The hardness changes of the X210Cr12 tool steel after quenching and tempering are documented in Table 2.
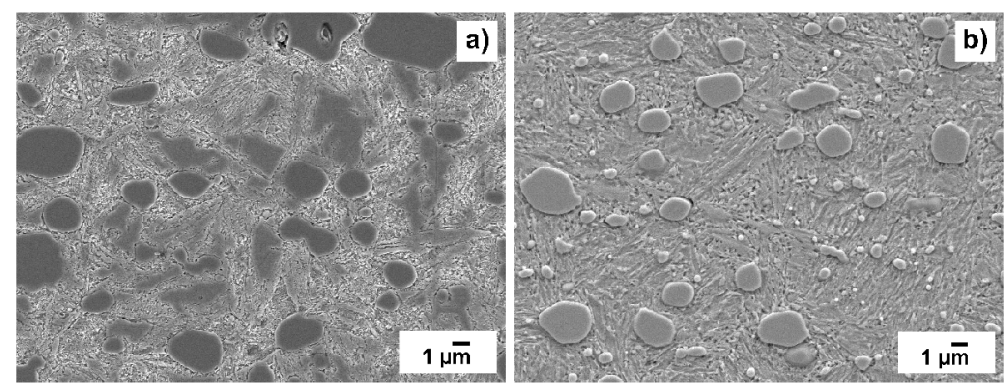

Figure 3. Microstructure of $\mathrm{X} 210 \mathrm{Cr} 12$ tool steel after: “A” treatment (a); and “C" treatment (b).

Table 2. Hardness of the tested samples after heat treatment (HRC).

\begin{tabular}{ccc}
\hline Heat Treatment & After Quenching & After Tempering \\
\hline "A" & $62 \pm 1$ & $61 \pm 1$ \\
"C" & $53 \pm 0.8$ & $57 \pm 0.8$ \\
\hline
\end{tabular}

After both the quenching and tempering regimes, half portions of the samples were nitrided. Light optical micrographs of the nitrided layers after nital etching are shown in Figure $4 \mathrm{a}, \mathrm{b}$. Their details are visualized on the SEM images in Figure 5a,b.

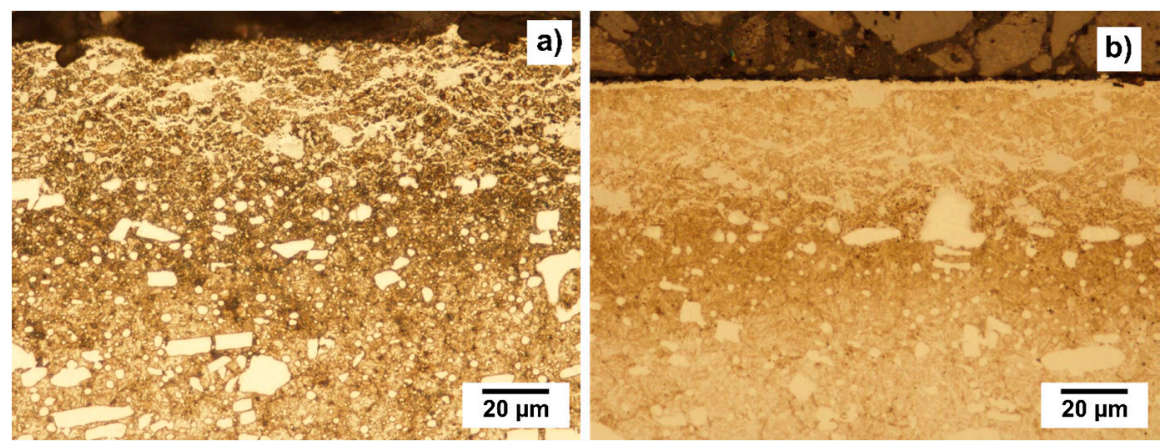

Figure 4. Steel X210Cr12 nitrided layer after: “B” treatment (a); and “D” treatment $(\mathbf{b})$.

It can be seen in Figure 4a that the nitrided steel layer exhibits white "nets" occurring around the carbides. Such "netting" was also observed and evaluated in the study [20] on D2 steel, closely related to X210Cr12 steel. The "nets" occurred around the carbides and grain boundaries even when plasma nitriding was used. In Figure $4 \mathrm{~b}$ the nitrided layer after " $\mathrm{D}$ " treatment shows shorter "nets" and also their reduced amount compared to the layer after the "B" treatment. 

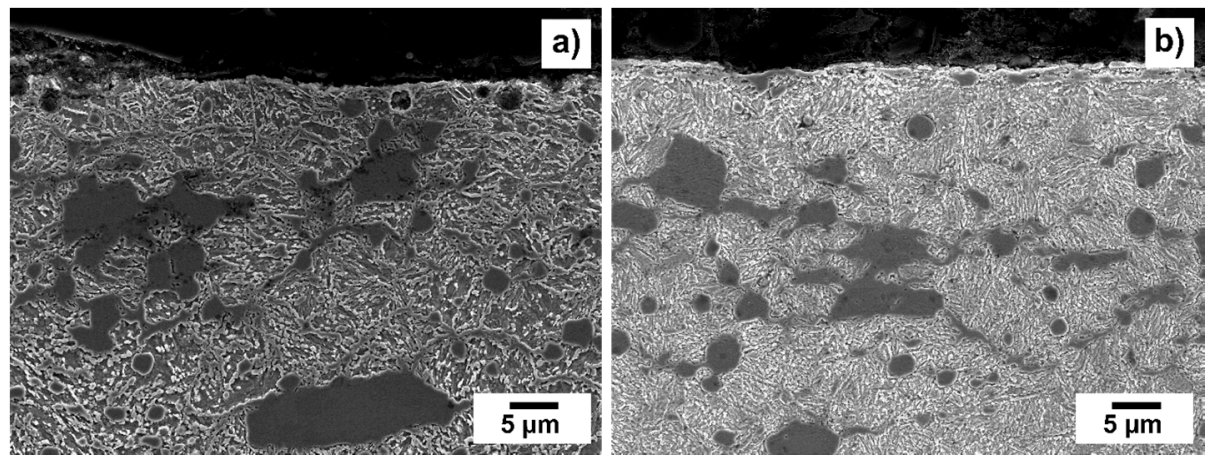

Figure 5. Details of $\mathrm{X} 210 \mathrm{Cr} 12$ steel nitrided layer after: " $\mathrm{B}$ " treatment (a); and " $\mathrm{D}$ " treatment (b).

By an EDX analysis, the thin elongated shapes were studied. As can be seen from the EDX measurement (Figure 6), the elongated shapes are related to complex $\mathrm{Fe}-\mathrm{Cr}$ carbides. These elongated carbides are relatively thin compared to the primary carbides. The formation of thin elongated $\mathrm{Fe}-\mathrm{Cr}$ carbides is likely enhanced by the process of nitriding. This phenomenon has to be studied more in detail.
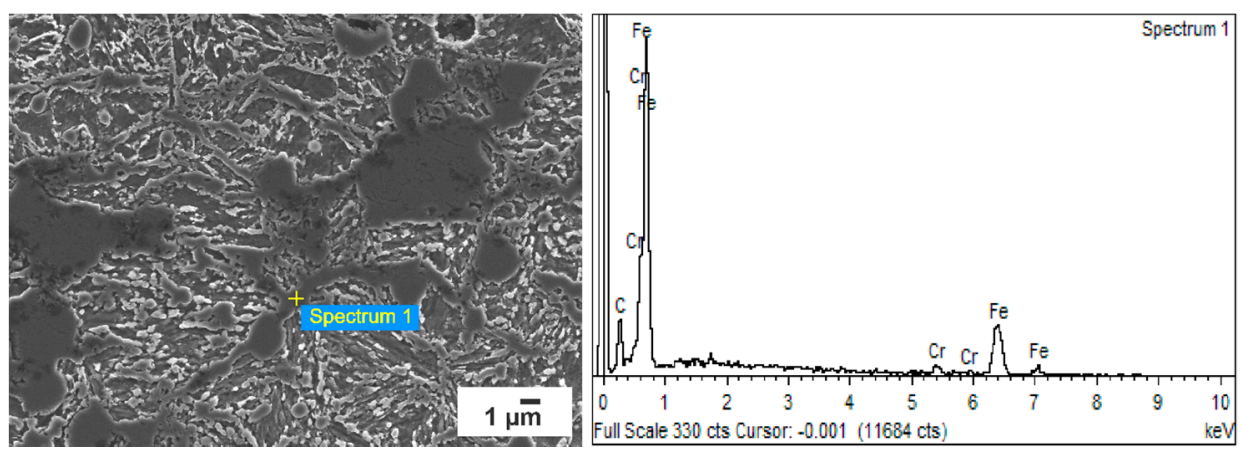

Figure 6. EDX analysis of an elongated shape in the nitrided layer after " $B$ " treatment.

\subsection{Mechanical Properties}

The microhardness profiles of the layers are documented in Figure 7. The hardness of the samples after " $\mathrm{A}$ " treatment before nitriding was $61 \mathrm{HRC}$, and after nitriding (" $\mathrm{B}$ ") the maximum hardness of the layer was $860 \mathrm{HV}_{0.05}$, which corresponds to approximately $63 \mathrm{HRC}$.

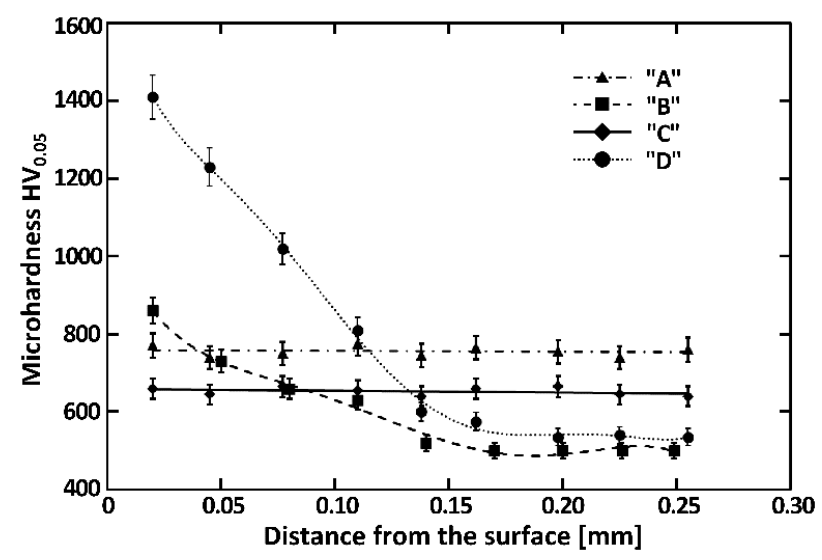

Figure 7. Microhardness vs. layer depth of the tested samples. 
The effective case depth in this case was about $0.13 \mathrm{~mm}$ and the core hardness was $500 \mathrm{HV}_{0.05}$ (approx. $50 \mathrm{HRC}$ ). The hardness drop was caused by the softening of the matrix during nitriding, which is a common feature. After the "C" treatment, the hardness of the sample was $57 \mathrm{HRC}$. After the nitriding (" $\mathrm{D}$ "), the maximum hardness of the layer was almost $1410 \mathrm{HV}_{0.05}$, which corresponds to approximately $73 \mathrm{HRC}$. The effective case depth in this case was about $0.17 \mathrm{~mm}$ and the core hardness was $550 \mathrm{HV}_{0.05}$ (approx. $54.5 \mathrm{HRC}$ ). The core hardness showed a slight drop by a value of $2.5 \mathrm{HRC}$.

\subsection{Abrasion Wear Resistance}

All treated samples were subjected to abrasion wear tests. The average weight losses of the tested samples are documented in Figure 8.

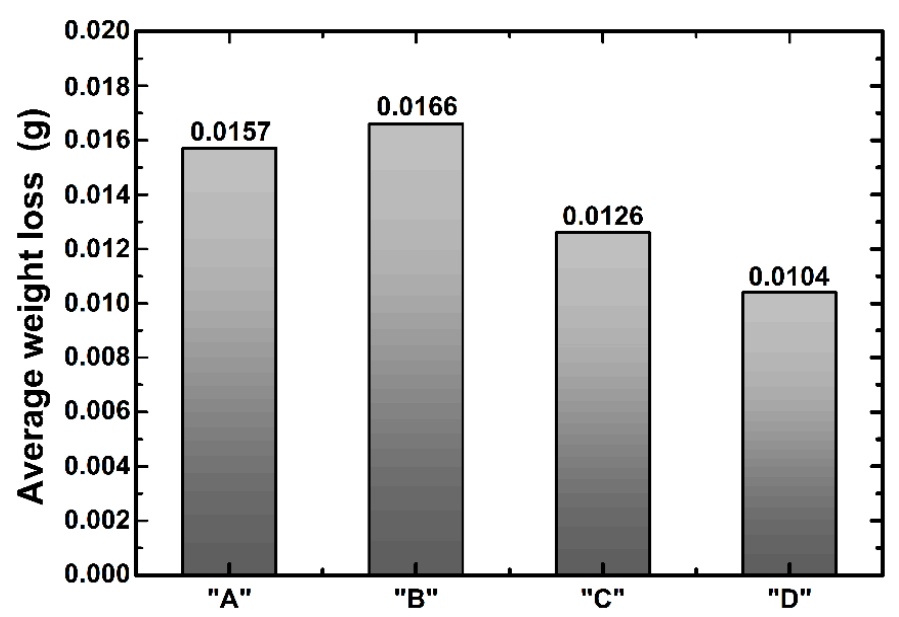

Figure 8. Average weight loss of tested samples after abrasion wear test.

It might be expected that the greatest weight loss should be achieved by the samples with the lowest hardness. However, as shown in Figure 8, the most significant weight loss was measured for samples after the " $\mathrm{B}$ " treatment with a maximum microhardness of $860 \mathrm{HV}_{0.05}$. This result was rather surprising since the material hardness was higher compared to the samples after both the " $\mathrm{A}$ " and "C" treatments.

The hardness of the samples with primary carbides in the microstructure after the " $\mathrm{A}$ " treatment was $61 \mathrm{HRC}$. The hardness of samples with secondary carbides in the microstructure after the " $\mathrm{C}$ " treatment was 57 HRC. As can be seen in Figure 8, the weight loss of the sample after the " $\mathrm{C}$ " treatment was approximately $20 \%$ smaller compared to the samples after the " $\mathrm{A}$ " treatment. This is caused by more suitable martensitic microstructure with finer carbides, higher saturation of martensite and the fact that the carbides have better adhesion bonds with the matrix.

The samples after the " $\mathrm{D}$ " treatment showed the lowest weight loss from all the samples. The hardness of the layer was the highest of all the specimens; the nitrided layer was continuous and free of defects. The high hardness of the layer was achieved due to the higher amounts of chromium and carbon saturated in the matrix. This enabled the formation of hard complex nitrides.

To understand the wear mechanisms, SEM photographs of the worn surfaces have been analyzed. The worn surfaces are documented in Figure 9.

The samples after the " $\mathrm{A}$ " treatment were worn by a combination of abrasion and delaminating. The delaminating is caused by the retained austenite $(24 \mathrm{vol} \%)$ in the microstructure. The samples after the " $\mathrm{C}$ " treatment show almost the same profile. The surface was worn mainly by abrasion and delaminating. In this case, the delaminating occurred due to the lower hardness of the martensitic matrix ( $57 \mathrm{HRC}$ ). In the case of the samples after the " $\mathrm{B}$ " treatment, the surface was worn mainly by abrasion and some delaminating was also observed. In this case, some irregular patterns were observed when compared to the other surfaces. Therefore, a contrast image was used to document 
these patterns together with EDX analysis as shown in Figure 10. The patterns on the contrast image are created around the holes. The local EDX analysis of a selected pattern showed the increased contents of chromium, carbon and nitrogen. This indicates that the holes represent the original positions of the coarse primary carbides in the microstructure. These carbides were mechanically removed from the surface during the abrasion test due to their weaker adhesion bonds with the matrix. Thus the loss of carbides from the matrix resulted in lower abrasion wear resistance. Moreover, the reduction in abrasive wear resistance was likely accelerated by the presence of elongated complex Fe-Cr carbides showing easy chips formation. The main wear type of the samples after the " $\mathrm{D}$ " treatment was abrasion cutting due to the high hardness of the nitrided layer. The number of delaminating patterns was negligible.

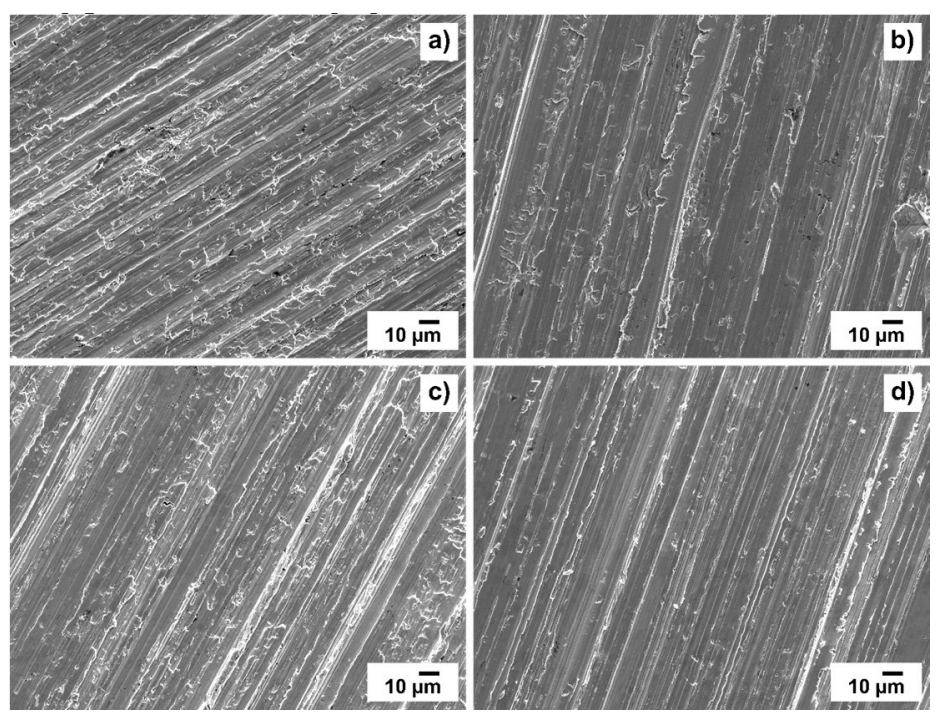

Figure 9. Worn surfaces after abrasion tests of $\mathrm{X} 210 \mathrm{Cr} 12$ steel after: " $\mathrm{A}$ " treatment (a); " $\mathrm{B}$ " treatment $(\mathbf{b}) ;$ " $C$ " treatment $(\mathbf{c}) ;$ " $\mathrm{D}$ ” treatment $(\mathbf{d})$.

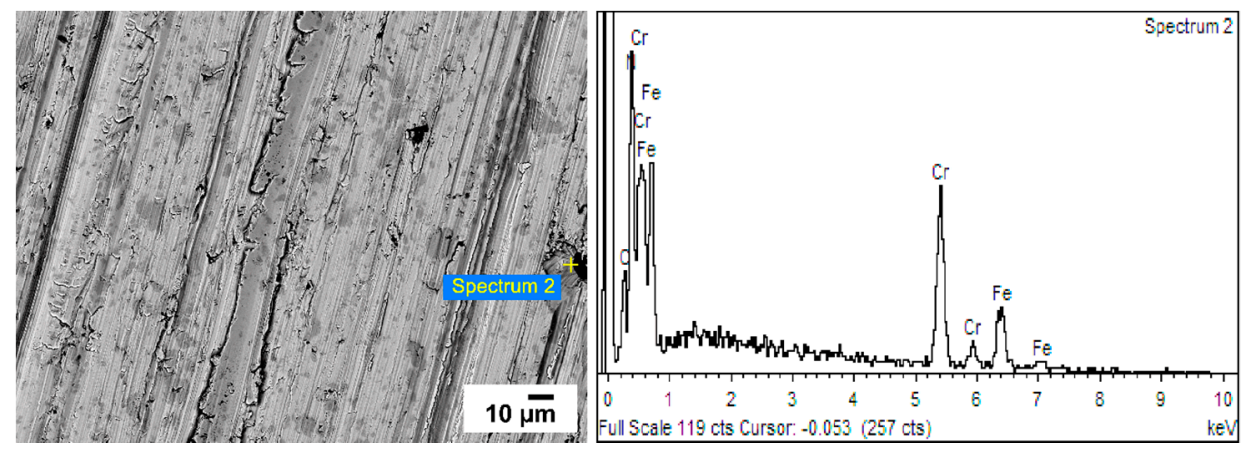

Figure 10. Worn surface after the “ $\mathrm{B}$ " treatment and EDX spectrum from a pushed pattern.

\section{Conclusions}

In this work, the influence of combinations of heat treatment and gas nitriding with diffusion annealing was tested on X210Cr12 tool steel and its resistance to abrasive wear. From the obtained results, it is possible to state the following conclusions:

- Quenching the steel from a lower temperature preserved the primary carbides and high carbon content in microstructure resulting in retained austenite stabilization and higher wear rates.

- Quenching and tempering the steel at higher temperatures to achieve its secondary hardness resulted in a martensitic microstructure with fine carbides and higher carbon and chromium 
saturation of the martensitic matrix. Compared to the previous treatment the steel showed lower weight loss, even though its hardness was lower (57 HRC).

- Nitriding of the steel containing primary carbides produced a harder layer compared to the quenched and tempered state with thin elongated Fe-Cr carbides. However, this type of treatment was found to be very unsatisfactory due to the mechanical removing of primary carbides during abrasion test resulting in the lowest abrasion wear resistance.

- Nitriding the steel that was quenched and tempered at higher temperatures for achieving secondary hardness was very beneficial. The hard and uniform nitrided layer improved the abrasion wear resistance as the weight loss of the sample was the lowest. This result was achieved via finer carbides size and their proper morphology, higher saturation of martensite with chromium and carbon after the quenching stage and small amount of retained austenite.

In the present study, it has been revealed that the samples of $\mathrm{X} 210 \mathrm{Cr} 12$ tool steel with fine matrix microstructure, fine carbide size and proper morphology may exhibit higher abrasion wear resistance despite their lower hardness values compared to the microstructure with coarse primary carbides. Nitriding treatment of the samples showed that this process can increase their surface hardness and change the wear mechanism. However, in the case of its application for inappropriate initial microstructures, the abrasive wear resistance may be decreased.

Acknowledgments: This work was financially supported by the project VEGA 2/0081/16.

Author Contributions: M.O. conceived the study, wrote the paper, performed the abrasive wear tests, evaluated tests and measured the retained austenite of the samples. M.B. preformed the heat treatment and nitriding of the samples. M.Š. and L.F. performed the microstructural analyses of the tested samples and measured the microhardness of the samples. All authors read and approved the manuscript.

Conflicts of Interest: The authors declare no conflict of interest.

\section{References}

1. Hutchings, I.M. Tribology-Friction and Wear Enginnering Material; CRC Press: London, UK, 1992.

2. Sapate, S.G.; Chopde, A.D.; Nimbalkar, P.M.; Chandarkar, D.M. Effect of microsturcture on slury abrasion response of En-31 steel. Mater. Des. 2007, 28, 1923-1927.

3. Sevim, I.; Eryurek, I.B. Effect of abrasive particle size on wear resistance in non-heat-treated steels. Kov. Mater. 2005, 43, 158-168.

4. Blau, P.J.; Dehoff, R.R. Development of a two-body wet abrasion test method with attentation to the effects of reused abradant. Wear 2013, 302, 1035-1039. [CrossRef]

5. Deng, X.T.; Wang, Z.D.; Han, Y.; Zhao, H.; Wang, G.D. Microstructure and abrasive wear behavior of medium carbon low alloy martensitic abrasion resistant steel. J. Iron Steel Res. 2014, 21, 98-103. [CrossRef]

6. Ruffing, C.; Kersher, E.; Courtois-Manara, E.; Prang, R.; Kübel, C.; Ivanisenko, Y.; Kerscher, E. Fatigue Behaviorof ultrafine-grained medium carbon steel with different carbide morphologies processed by high pressure torsion. Metals 2015, 5, 891-909. [CrossRef]

7. Gural, A. Influence of martensite particle size on dry sliding wear behavior pm low carbon dual phase powder metallurgy steals. Kov. Mater. 2010, 48, 25-31.

8. Bakshi, S.D.; Bhadeshia, H.K.D.H.; Shipway, P.H. Three-body abrasive wear of fine pearilite, nanostrucutred bainite and martensite. Wear 2013, 308, 46-53. [CrossRef]

9. Singh, K.; Khatirkar, R.K.; Sapate, S.G. Microstructure evolution and abrasive wear behavior of D2 steel. Wear 2015, 328-329, 206-216. [CrossRef]

10. Ooi, S.; Bhadeshia, H.K.D.H. Duplex hardening of steels for aero engine bearings. ISIJ Int. 2012, 52, $1927-1934$. [CrossRef]

11. Yeh, S.H.; Chiu, L.H.; Chang, H. Effects of gas nitriding on the mechanical and corrosion, properties of SACM 645 Steel. Engineering 2011, 3, 942-948. [CrossRef]

12. Rabinowicz, E. Friction and Wear of Materials; Wiley: New York, NY, USA, 1965. 
13. Guagliano, M.; Moridia, A.; Guaglianoa, M.; Ghidinib, A.; Boniardia, M. The effect of nitriding, severe shot peening and their combination on the fatigue behavior and micro-structure of low-alloy steel. Int. J. Fatigue 2014, 62, 67-76.

14. Ashrafizadeh, F. Influence of plasma and gas nitriding on fatigue resistance of plain carbon (Ck 45) steel. Sur. Coat. Technol. 2003, 173-174, 1196-1200.

15. Podgornik, B.; Vižntin, J.; Leskovšek, V. Wear properties of induction hardened, conventional nitrided and pulse plasma nitrided AISI 4140 steel in dry slury sliding conditions. Wear 1999, 232, 231-242. [CrossRef]

16. Karamis, M.B.; Yildizli, K.; Aydin, G.C. Sliding/rolling wear performance of plasma nitrided H11 hot working steel. Tribol. Int. 2012, 51, 18-24. [CrossRef]

17. Orecny, M.; Bursak, M.; Vinas, J. The influence of heat treatment on the abrasive wear resistance of a construction and tool steel. Metallurgy 2015, 54, 191-193.

18. Zabavnik, V.; Bursak, M. Quenching and Quality Control of Materials; Emilena: Košice, Slovakia, 2004.

19. Material X210Cr12 Data List. Available online: www.bohlerturkiye.com/K100DE.pdf (accessed on 21 September 2016).

20. Conci, M.D.; Bozzib, A.C.; Franco, A.R., Jr. Effect of plasma nitriding potential on tribological behaviour of AISI D2 cold-worked tool steel. Wear 2014, 317, 188-193. [CrossRef]

(C) 2016 by the authors; licensee MDPI, Basel, Switzerland. This article is an open access article distributed under the terms and conditions of the Creative Commons Attribution (CC-BY) license (http://creativecommons.org/licenses/by/4.0/). 